\title{
Genotoxicity of diuron and glyphosate in oyster spermatozoa and embryos
}

\author{
F. Akcha*, C. Spagnol, J. Rouxel
}

Ifremer, Department of Biogeochemistry and Ecotoxicology, Laboratory of Ecotoxicology, Rue de I'lle d'Yeu, BP 21105, 44311 Nantes Cedex 03, France

*: Corresponding author : Farida Akcha, Tel.: +332403742 08 ; fax: +332403742 41 ; email address : fakcha@ifremer.fr

\begin{abstract}
:
We investigated the effects of genotoxicant exposure in gametes and embryos to find a possible link between genotoxicity and reproduction/developmental impairment, and explore the impact of chemical genotoxicity on population dynamics. Our study focused on the genotoxic effects of two herbicides on oyster gametes and embryos: glyphosate (both as an active substance and in the Roundup formulation) and diuron. France is Europe's leading consumer of agrochemical substances and as such, contamination of France's coastal waters by pesticides is a major concern. Glyphosate and diuron are among the most frequently detected herbicides in oyster production areas; as oyster is a specie with external reproduction, its gametes and embryos are in direct contact with the surrounding waters and are hence particularly exposed to these potentially dangerous substances.
\end{abstract}

In the course of this study, differences in genotoxic and embryotoxic responses were observed in the various experiments, possibly due to differences in pollutant sensitivity between the tested genitor lots. Glyphosate and Roundup had no effect on oyster development at the concentrations tested, whereas diuron significantly affected embryo-larval development from the lowest tested concentration of 0.05 $\mu \mathrm{g} L-1$, i.e. an environmentally realistic concentration. Diuron may therefore have a significant impact on oyster recruitment rates in the natural environment.

Our spermiotoxicity study revealed none of the tested herbicides to be cytotoxic for oyster spermatozoa. However, the alkaline comet assay showed diuron to have a significant genotoxic effect on oyster spermatozoa at concentrations of $0.05 \mu \mathrm{g} \mathrm{L}-1$ upwards. Conversely, no effects due to diuron exposure were observed on sperm mitochondrial function or acrosomal membrane integrity. Although our initial results showed no negative effect on sperm function, the possible impact on fertilization rate and the consequences of the transmission of damaged DNA for oyster development and physiological performances, requires further investigation. A likely hypothesis to explain the embryotoxic and genotoxic effects of diuron is that it may act via causing oxidative stress.

\section{Highlights :}

- The embryotoxic and genotoxic effects of diuron, glyphosate and Roundup were studied in oyster. - Only diuron affected embryo-larval development from the lowest concentration of $0.05 \mu \mathrm{g} \mathrm{L-1}$. Compared with the two others, diuron was also genotoxic for spermatozoa at $0.05 \mu \mathrm{g} \mathrm{L}-1$ upwards. Conversely, it did not affect sperm mitochondrial function or acrosomal membrane integrity.

Keywords : Genotoxicity ; Embryotoxicity ; Oyster ; Gametes ; Pesticides ; Diuron ; Glyphosate 


\section{Introduction}

France is Europe's leading consumer of agrochemical substances (UIPP, 2006). Due to the intensive use and transfer of these substances to exoreic catchment areas, several pesticides have been detected in recent years in coastal waters, including shellfish production areas (Burgeot et al., 2008). Pesticides can enter aquatic systems via periodic inputs from accidental or controlled sources (urban and industrial discharges), but also from diffuse sources originating from domestic and agricultural activities. The contamination of France's continental and marine waters by pesticides is mainly due to agriculture, and most of the molecules involved are herbicides.

Little data exists on the contamination of coastal waters by herbicides. Some data have been collected in the Marennes-Oleron basin, which is one of France's largest natural spat harnessing zones (Munaron, 2004, Samain et al., 2007). Contamination of this basin has been shown to be highly dependent on herbicide fluxes from the Charentes river, due to farming activity and heavy rainfall. Among the active substances found in this basin, diuron, isoproturon and glyphosate were the most frequently-detected, and at the highest concentrations. These molecules were respectively detected at $0.04,0.40 \mathrm{\mu gL}^{-1}$ and 1.20 $\mu \mathrm{gL}^{-1}$ in this basin.

The presence of herbicides in marine waters is an environmental issue, as many have been shown to be toxic for marine organisms. Once in water bodies, herbicides and/or their byproducts may be bioavailable for the organisms. Depending on their lipophilic property, their absorption may lead to the bioaccumulation in fatty tissue of molecules with an octanol/water partition coefficient (Kow) higher than three (GESAMP, 2002). In some cases, bioaccumulation may be limited by the organism's ability to biotransform the molecules into more readily-excretable residues. However, biotransformation can also lead to the production of residues that are even more toxic than the parent active substances (Binelli et al., 2008). Diverse toxic effects have been reported for pesticides such as herbicides, and the genotoxic (Bouilly et al., 2007, Wessel et al., 2007), embryotoxic (Wessel et al., 2007, Manzo et al., 2006), immunotoxic (Gagnaire et al., 2006, 2007) and reprotoxic (Salaberria et al., 2009, Rodriguez et al., 2007) effects of them on fish and bivalves have already been unveiled. There is therefore a need for a more efficient assessment of the environmental risks associated with pesticides, which represent 11 out of the 33 dangerous substances identified by the European Water Framework Directive (2000/60/CE).

The aquaculture industry has expressed particular concern about a possible link between oyster mortality outbreaks and pollution. Oyster mortality has been repeatedly observed in France for several years now, with major socioeconomic consequences. France is respectively Europe's first and the world's fourth leading producer of oysters, with an annual production of 130,000 metric tons. The suspected role of pollution in oyster mortality was pinpointed by the Samain et al. study (2007), which used a multifactorial interaction model taking into account commensal and pathogenic microorganisms, oyster physiological and genetic status, and the environment (biotic factors). The study revealed that oyster mortality could not be put down to contamination by pathogenic agents (herpes virus or vibrio bacteria) alone. Oysters were shown to be particularly vulnerable to physiological and environmental stressors during gametogenesis, when energy is dedicated to reproduction rather than immune defence. Significant pesticide inputs were observed in the Marennes-Oléron basin, and the highest concentrations were detected in June, corresponding to both oyster gametogenesis and to the mortality outbreaks. It can thus be considered that oyster exposure to pollutants such as pesticides could have direct toxic effects on individuals (spat, juveniles and genitors), with a potential indirect effect on offspring related to genitor contamination during gametogenesis. In addition, as oyster is a specie with external reproduction, its gametes and embryos are in direct contact with sea water and are therefore particularly vulnerable to toxic substances. 
Another point is the increasing number of studies that are demonstrating interactions between chemical pollution and infectious diseases (Morley, 2009). Exposure to chemical pollutants can result either in a decline in individual resistance to pathogens, or to a direct impact on the immune system (immunosuppression, immunostimulation or autoimmune diseases). Conversely, the presence of pathogens can alter the physiology of the organism and hence its ability to modulate the toxicity of chemical pollutants. Interactions between the immune system and the biotransformation of chemical pollutants have already been demonstrated in fish (Reynaud et al., 2008).

In this paper, we focused our research on the effects of three herbicides - diuron, glyphosate and Roundup - on oyster sperm and embryos. Diuron is a broad-spectrum substituted urea herbicide, identified as a dangerous substance by the WFD. It is fairly persistent in aquatic systems as it shows no degradation in seawater at $15^{\circ} \mathrm{C}$ over 42 days (Thomas et al., 2002). Despite its restricted use, diuron remains one of the most frequently-detected and most highly-concentrated herbicides found in coastal waters (Munaron, 2004). Glyphosate is currently the world's most highly-used herbicide (Woodburn, 2000). As this active substance is not employed on its own, it appeared valuable to study its toxicological properties in parallel with its well-known commercial formulation: Roundup. The embryotoxic effects of these herbicides were studied through various embryo-larval bioassays. Cytotoxicity and genotoxicity in spermatozoa were respectively assessed using classical and flow cytometry analysis, and the alkaline comet assay. The potential impact of diuron exposure on sperm function (sperm mitochondrial function and acrosomal membrane integrity) was also investigated.

\section{Material and methods}

\subsection{Chemicals and material}

The reference sea water used for the experiments was pumped from Argenton (Brittany, France) and filtered at $0.22 \mu \mathrm{m}$ before use. Dimethyl sulfoxide (DMSO), acetonitrile, formaldehyde $36.5 \%$, normal and low melting point agarose, collagenase, Triton X-100 and diuron (100 ng $\mathrm{L}^{-1}$ in acetonitrile) were purchased from Sigma Aldrich Chemicals. The certified solution of glyphosate $\left(10 \mathrm{ng}^{-1} \mathrm{~L}^{-1}\right)$ was purchased from VWR. Roundup Express $®$ was bought at a garden centre. PrestoBlue Cell viability reagent, MitoTracker Red CMXRos, Alexa488-conjugated Arachis hypogaea lectin (Alexa488-PNA) and the Live/Dead Sperm viability assay were from Invitrogen. ATP Lite was purchased from Perkin Elmer.

\subsection{Animals}

The test oysters came from a hatchery specialized in the production of organisms for bioassay monitoring (Guernsey sea farm, UK). Mature oysters were stored at $4^{\circ} \mathrm{C}$ and used for our experiments within three days.

\subsection{Gamete recovery}

Spawning from both sexes was induced in the laboratory by scarification of the gonads using a surgical scalpel. This method enabled fast gamete recovery in the reference sea water. Following rehydratation for $30 \mathrm{~min}$ in sea water, the oocytes and the spermatozoa were sieved at 100 and $32 \mu \mathrm{m}$ respectively, and observed under an inverted microscope. 


\subsection{Embryotoxicity study}

The embryotoxic effects of pesticide exposure were studied using the embryo-larval bioassay, in accordance with the standardized AFNOR procedure (AFNOR XP-T-90-382) published in September 2009. Three bioassays were performed for each herbicide at one month interval, as described below.

\subsubsection{Fertilization}

Oocytes from one female were fertilized using a sperm-dense suspension from a male, with a ratio of 10 spermatozoa per oocyte. $15 \mathrm{~min}$ after fertilization, the embryos were counted and dispatched in each assay beaker, to reach a final concentration of 50,000 fertilized eggs per litre.

\subsubsection{Chemical exposure}

After fertilization, the embryos were placed in contaminated sea water in order to study the embryotoxic effects of the selected herbicides. Glyphosate and Roundup are water-soluble, whereas diuron is sold in an acetonitrile-based solution. Stock solutions of diuron $\left(2 \mathrm{mgL}^{-1}\right)$, glyphosate $\left(200 \mu \mathrm{gL}^{-1}\right)$ and Roundup $\left(200 \mu \mathrm{g}\right.$ equivalent glyphosate $\left.\mathrm{L}^{-1}\right)$ were prepared and stored at $-20^{\circ} \mathrm{C}$ in the dark in glass and plastic tubes respectively. For the experiments, these working solutions were then diluted to reach the final tested concentrations. For diuron, the acetonitrile concentration in sea water was $0.005 \%$. Two controls were prepared for the purpose of our experiments: a sea water control for glyphosate and Roundup, and a solvent control $(0.005 \%$ acetonitrile $)$ for diuron.

Various concentrations were taken into account for diuron and glyphosate/Roundup, all within the range of the environmental concentrations already found in coastal waters, with the exception of the two highest glyphosate concentrations (Table 1). For Roundup, it is noteworthy that concentrations are expressed in $\mu \mathrm{g}$ of equivalent glyphosate per liter.

\subsubsection{Embryonic development}

After fertilization, the embryos were developed for $24 \mathrm{~h}$ in the dark at a temperature of $24^{\circ} \mathrm{C}$, in beakers containing $30 \mathrm{~mL}$ of filtered sea water (three replicates for each control and herbicide-exposed group). This incubation time enabled the embryos to develop up to the Dshell stage. Following exposure, the larvae from each beaker were fixed using $8 \%$ formol $(0.5 \mathrm{~mL} /$ beaker $)$. One hundred larvae from each beaker were observed under an inverted microscope (x 20) to determine the numbers of D-larvae showing mantle and/or shell abnormalities (Figure 1).

\subsection{Cytotoxic and genotoxic effects of pesticides on oyster spermatozoa}

\subsubsection{Exposure of oyster spermatozoa to the selected herbicides}

Three independent experiments were performed for each herbicide. Sperm from two males was used for each experiment. Following scarification, the sperm was diluted in filtered reference sea water to reach a final concentration of about 35 millions per $\mathrm{mL}$. Three replicates were made for each concentration by exposing $10 \mathrm{~mL}$ of sperm for $1 \mathrm{~h}$ at $17^{\circ} \mathrm{C}$. 
The herbicide concentrations were the same as those used for the embryotoxicity study, with the exception of diuron, which was tested at an additional concentration of $1.5 \mathrm{\mu gL}^{-1}$ (Table 1). Sperm was also exposed to a range of $\mathrm{H}_{2} \mathrm{O}_{2}$ concentrations (1-h exposure, 5-50 $\mu \mathrm{M}$ ); $\mathrm{H}_{2} \mathrm{O}_{2}$ is a direct genotoxicant, used as a positive control for the comet assay.

\subsubsection{Effects of herbicide exposure on sperm viability}

Sperm viability was systematically measured in each experiment to assess the potential cytotoxic effects of herbicides and to legitimate the use of the alkaline comet assay as a reliable genotoxicity assessor. Viability was assessed by means of two different tests:

Titration of intracellular ATP content: Intracellular Adenosine TriPhosphate (ATP) titration is considered to be a marker of cell viability, due to its presence in all metabolically-active cells. In our study, ATP titration was performed using a luminescence ATP detection assay (ATPlite by PerkinElmer) based on light produced by ATP reaction in the presence of luciferase and D-luciferin. The assay was performed on a 96-well microplate. One hundred $\mu \mathrm{L}$ of sperm solution was added to $50 \mu \mathrm{L}$ of cell lysis solution (total ATP) or sea water (extracellular ATP) in the presence of $50 \mu \mathrm{L}$ of substrate. After a 10-min incubation in the dark, the emitted light was measured using a 1420 Luminescence Counter from Perkin Elmer. Six wells were used for each sample, with 3 wells each for total and extracellular ATP.

Measurement of the reduction capability of sperm: Sperm viability can also be assessed by measuring its ability to reduce resazurin - a blue compound with no intrinsic fluorescent properties - to resorufin, which is red in colour and has fluorescent properties. For this purpose, we applied the PrestoBlue Cell Viability Reagent Protocol. $10 \mu \mathrm{L}$ of PrestoBlue Reagent were added to $90 \mu \mathrm{L}$ of the sperm solution, which was then incubated for $10 \mathrm{~min}$ at $37^{\circ} \mathrm{C}$. Three wells of a 96-well microplate were used per sample. Fluorescence was subsequently measured with a Tecan microplate reader, using fluorescence excitation and emission values of 535 and $615 \mathrm{~nm}$ respectively.

\subsubsection{Effects of herbicide exposure on spermatozoa DNA integrity}

DNA integrity was assessed by measuring DNA strand breakage using the alkaline comet assay. After exposure, $100 \mu \mathrm{L}$ of sperm solution was pipetted out from each of the three replicates, then diluted with filtered sea water (1/2 dilution). The diluted sperm solution was then used for the comet assay as described in Akcha et al. (2003). DNA unwinding was performed by pre-incubating the slides in a freshly-prepared electrophoresis buffer $(0.3 \mathrm{M}$ $\mathrm{NaOH}, 0.001 \mathrm{M}$ EDTA, $\mathrm{pH} 13$ ) for $15 \mathrm{~min}$ in the dark at room temperature. DNA migration was performed in the same buffer for $20 \mathrm{~min}$ at $23 \mathrm{~V}\left(390 \mathrm{~mA}, \mathrm{E}=0.66 \mathrm{~V} . \mathrm{cm}^{-1}\right)$. After electrophoresis, the slides were washed by incubation for $3 \times 5$ min in Tris base $0.4 \mathrm{M}, \mathrm{pH}$ 7.5. In order to obtain permanent preparations, the slides were dehydrated for $10 \mathrm{~min}$ in absolute ethanol, then allowed to dry at room temperature. Immediately before analysis, 75 $\mu \mathrm{L}$ of ethidium bromide at $10 \mu \mathrm{gmL}^{-1}$ were deposited on the slide and spread over it using a cover glass. The slides were analysed using an optical fluorescence microscope (Olympus BX60, x40) fitted to a CDD camera (Luca S, Andor Technology) and coupled to an image analysis system (Komet 6, Kinetic Imaging Ltd). Several parameters were calculated for each observed nucleus (75 nuclei/slide), including the percentage of DNA present in the comet tail (\% Tail DNA). 


\subsection{Effects of diuron exposure on sperm viability and function: flow cytometry analysis}

A separate experiment was conducted with the aim of checking the potential effects of diuron exposure on sperm viability and function using flow cytometry. For this study, sperm from two males was collected and exposed to diuron ( $1 \mathrm{~h}$ exposure, $0.05,0.10$ and $0.50 \mu \mathrm{gL}^{-1}$ ) as described previously.

Flow cytometry was used to study the effects of diuron exposure on both sperm viability and function (mitochondrial function and acrosomal membrane integrity), using the protocols described by Favret and Lynn (2010) for sperm analysis of three aquatic invertebrates, including the oyster.

Sperm viability: Sperm viability was assessed by applying the Live/Dead Sperm Viability Assay (Molecular Probes). SYBR -14, which is a membrane-permeate nucleic acid stain, was used to label live sperm cells with intact membranes (green fluorescence), and propidium iodide $(\mathrm{PI})$ was used to label cells with damaged membranes (red fluorescence). Each sperm sample was incubated for 10 min in the dark with $20 \mathrm{nM}$ of SYBR-14. $12 \mu \mathrm{M}$ of PI were then added and incubation was prolonged for 10 more min.

Sperm mitochondrial function: Mitochondrial function was assessed using MitoTracker Red CMXRos. This dye has red fluorescent properties that stain mitochondria in live cells. Assessment of this parameter offers a good alternative to visual estimates of sperm motility, which can vary widely (Marchetti et al., 2004).

Acrosomal membrane integrity of spermatozoa: Acrosomal reaction was measured by positive staining with Alexa488-conjugated Arachis hypogaea (peanut) lectin (Alexa488PNA). PNA lectin is specific to terminal b-galactose moieties and cannot penetrate an intact acrosomal membrane. It only binds to the acrosome in acrosome-reacted or damaged spermatozoa, where it fluoresces green. Each sperm sample was incubated with $100 \mathrm{nM}$ of MitoTracker Red CMXRos for $10 \mathrm{~min}$ in the dark. Alexa488-PNA were then added at a final concentration of $5 \mu \mathrm{gmL}^{-1}$ and incubation was prolonged for 10 more min.

Cytofluorimetric analyses of the sperm samples were conducted using a C6 Flow Cytometer (Accuri Cytometers, Inc., Ann Arbor, MI) equipped with a solid state 488-nm laser. A total of 30,000 events were analyzed for each triplicate (3 replicates per sample) using Cflow software (Accuri Cytometers, Inc., Ann Arbor, MI). All measurements were done in triplicate.

Each set of data was analyzed as the percentage of sperm found in the gated regions where dye fluorescence was detected. SYBR-14 and Alexa488-PNA fluorescence were detected on the FL1 channel using a $530 \pm 15-\mathrm{nm}$ interference filter. PI and MitoTracker Red CMXRos fluorescence were detected on the FL3 channel using a 675-nm long-pass filter.

\section{Results}

\subsection{Study of the potential embryotoxic effects of diuron, glyphosate and Roundup}

For the three herbicides, a one-way ANOVA was performed to analyse the data from each bioassay, taking "herbicide concentration" as a factor. A second main effects ANOVA was then performed with the 3 sets of data to describe the main effects and interactions of both "herbicide concentration" and "bioassay experiment" factors. 


\subsubsection{Diuron}

The three independent embryo-larval bioassays revealed diuron to have embryotoxic effects on oyster embryo, with some differences (Figure 1). Embryotoxicity was detected at concentrations of $0.05 \mathrm{\mu gL}^{-1}$ upwards in the 2 nd and the 3rd bioassays $(p<0.001)$, whereas significant toxicity was detected at concentrations of $0.10 \mathrm{\mu gL}^{-1}$ upwards in the 1 st assay $(p<$ 0.001). An increase in the \% of abnormal D-larvae was observed in two out of the three bioassays when diuron concentrations were raised (significant increase at concentrations of between 0.1 and $0.5 \mathrm{\mu gL}^{-1}$ in the 1 st and the 2 nd bioassay).

Taking into account the data from the three bioassays, the main effects ANOVA revealed no significant differences between the assays $(p=0.19)$, but a highly-significant diuron effect ( $p$ $<0.001$ ) (Figure 2). Diuron embryotoxicity was confirmed after exposure to concentrations of $0.05 \mathrm{\mu gL}^{-1}$ upwards, and a significant increase in the number of abnormal D-larvae was observed at concentrations of between 0.05 and $0.25 \mu \mathrm{gL}^{-1}(p=0.006)$.

\subsubsection{Glyphosate}

Out of the three bioassays conducted at the laboratory, only one assay revealed glyphosate to have an embryotoxic effect at concentrations of $2.5 \mathrm{\mu gL}^{-1}(p<0.001)$ upwards. Taking into account the data from the three bioassays, the main effects ANOVA revealed significant differences between the assays ( $p<0.001$ ), with assay 2 differing from assays 1 and 3 (Figure 3). The ANOVA also pinpointed a significant interaction between "herbicide concentration" and "bioassay experiment" $(p=0.006)$. Significant differences were highlighted in terms of D-larvae abnormalities $(p<0.001)$, and results of an a posteriori Tukey test confirmed that exposure to glyphosate at concentrations of $5 \mu^{-1}$ leads to a significant increase in oyster embryo abnormalities versus the control $(p=0.009)$ (Figure 4$)$.

\subsubsection{Roundup}

The three independent embryo-larval bioassays showed Roundup to have no embryotoxic effects, even at the highest tested concentration of $5 \mu \mathrm{g}$ of equivalent glyphosate $L^{-1}(p=$ $0.15,0.38$ and 0.89 respectively). The main effects ANOVA performed with the 3 sets of data confirmed this finding ( $p=0.11$, Figure 5$)$. This analysis revealed significant differences between the bioassays $(p<0.001)$, but no significant interaction between "herbicide concentration" and "bioassay experiment" $(p=0.58)$.

\subsubsection{Glyphosate versus Roundup}

This comparison was done by analysing the 3 sets of data using a main effects ANOVA, taking into account three factors: bioassay experiment (1 to 3), herbicide type (glyphosate or Roundup) and herbicide concentration (5 concentrations and a sea water control). The ANOVA results confirmed the existence of differences between the bioassay experiments $(p$ $<0.001$ ). A significant interaction between "herbicide" and "herbicide concentration" factors $(p=0.015)$ was also pinpointed, in view of the differing results obtained with the active substance and its formulation. Despite glyphosate appears to have a weak embryotoxic effect, a significantly higher level of abnormal $D$-larvae was obtained following exposure to glyphosate versus Roundup ( $p<0.001)$. 


\subsection{Effects of herbicide exposure on sperm viability and DNA integrity}

\subsubsection{Effects of herbicide exposure on spermatozoa viability}

None of our viability tests revealed cytotoxic effects following a 1-h exposure to the three herbicides in the chosen concentration ranges. As for diuron, spermatozoa viability was higher than $80 \%$ and no differences were observed versus the control group (Figure 6). The only cytotoxic effect observed related to our $\mathrm{H}_{2} \mathrm{O}_{2}$ genotoxicity control, which resulted in a decrease in the intracellular ATP content of oyster spermatozoa following a 1-h exposure to a concentration of $50 \mu \mathrm{M}$.

\subsubsection{Effects of herbicide exposure on spermatozoa DNA integrity}

A significant increase in DNA strand breakage was measured in oyster spermatozoa after exposure to the direct genotoxicant $\mathrm{H}_{2} \mathrm{O}_{2}$, hence qualifying the alkaline comet assay for the assessment of pollutant genotoxicity in oyster spermatozoa (Figure 7). As described further on, genotoxicity results varied from one experiment to the next. However, the genotoxicity of $\mathrm{H}_{2} \mathrm{O}_{2}$ was systematically observed at a concentration of $50 \mu \mathrm{M}$ in our experiments, justifying its use as a positive control for the comet assay.

Genotoxicity of diuron in oyster spermatozoa: Two out of the three independent experiments we conducted illustrated the genotoxic effects of diuron on oyster spermatozoa at respective concentrations of $0.25{\mu \mathrm{gL}^{-1}}(p=0.003)$ and $0.50 \mathrm{\mu gL}^{-1}(p<0.001)$ upwards. The main effects ANOVA conducted on the three sets of data confirmed the existence of interexperimental variations $(p<0.001)$ and the significant genotoxicity of diuron $(p<0.001)$ : a non concentration-dependent increase in the level of spermatozoa DNA damage was demonstrated at the lowest concentration of $0.05 \mathrm{\mu gL}^{-1}$ upwards (Figure 8) using a Tukey test.

Genotoxicity of Glyphosate and Roundup in oyster spermatozoa: With the exception of one experiment, in which a higher level of DNA strand breakage was measured following exposure to $5.0 \mathrm{\mu gL}^{-1}$, glyphosate and Roundup did not appear to have any genotoxic effects on oyster spermatozoa at the concentrations tested. The main effects ANOVA performed on the three sets of data confirmed these findings $(p=0.11$ and $p=0.06$ respectively), plus the existence of inter-experimental variations ( $p<0.01$ for both herbicides).

\subsection{Effects of diuron exposure on sperm viability, mitochondrial function and acrosomal membrane integrity}

\subsubsection{Effects of diuron exposure on sperm viability and mitochondrial function}

Whatever the exposure concentration of diuron, no effect on sperm membrane integrity and mitochondrial function were observed with the Live/Dead sperm viability assay and the MitoTracker Red CMXRos assay respectively ( $p>0.05$ ). Conversely, exposure to our genotoxicity control significantly decreased both of these parameters, as illustrated in Figure 9. The results obtained with the MitoTracker Red CMXRos assay and the luminescence intracellular ATP titration assay were coherent as regards $\mathrm{H}_{2} \mathrm{O}_{2}$. 


\subsubsection{Effects of diuron exposure on sperm acrosomal membrane integrity}

Diuron had no effect on the acrosomal membrane integrity of oyster spermatozoa, whereas $\mathrm{H}_{2} \mathrm{O}_{2}$ exposure significantly affected this parameter, with wide variations $(62,76$ and $65 \%$ for the three replicates) (Figure 9).

\section{Discussion}

\subsection{Herbicide embryotoxicity}

The embryotoxicity of a broad variety of pollutants has been studied in bivalve molluscs and echinoderms thanks to the development of embryo-larval bioassays. The embryotoxic effects of several pesticides, including tributyltin, chlorpyrifos, lindane and other biocide compounds, have already been investigated in mussels and sea urchins (Kobayashi and Okamura, 2002, Bellas et al., 2005, Beiras et Bellas, 2008). Regarding oysters, the embryo-larval bioassay has previously been used for classical laboratory toxicity studies (Lyons et al., 2002, Wessel et al., 2007) and for field studies, with the aim of assessing marine water quality (Quiniou et al., 2007, Galgani et al., 2009).

The embryo-larval bioassay performed in our study showed Roundup to have no embryotoxic effects on oysters for the range of concentrations tested. Regarding glyphosate, the main effects ANOVA pinpointed a significant increase in the percentage of abnormal Dlarvae at concentrations of $5.00 \mathrm{\mu gL}^{-1}$ upwards. However, this concentration is well above the highest glyphosate concentrations (x 5) found in the natural environment (Burgeot et al., 2007). Moreover, this result complies with previous results obtained on oysters by De la Broise et al. (personal communication), the percentage of abnormal D-larvae was lower than $25 \%$ following exposure to the highest tested concentration of $5 \mathrm{mgL}^{-1}$ of glyphosate.

Very few studies exist on the impact of glyphosate on the development of aquatic species; most focus on the commercial formulation Roundup and use unrealistic glyphosate concentrations from an environmental viewpoint. In the freshwater snail, Pseudosuccinea columella, glyphosate in the Roundup formulation resulted in embryonic abnormalities at concentrations of 0.1 and $10 \mathrm{mgL}^{-1}$ (Tate et al., 1997). In the tadpole, Xenopus laevis, the only negative event detected on organ morphogenesis was a significant increase in intestinal malformations at an environmentally irrelevant concentration of $5.00 \mathrm{mgL}^{-1}$ (Lenkowski et al., 2010). Embryotoxicity and various malformations (cardiac and pericardic, digestivo-viteline and musculo-skeletic malformations) were also observed in zebrafish at glyphosate concentrations of $25 \mathrm{mgL}^{-1}$ upwards (Bortagaray et al., 2010).

Conversely, diuron appeared to be far more of a threat to the early development stages of the oyster. This molecule was shown to be embryotoxic at concentrations of $0.05 \mathrm{mgL}^{-1}$ upwards, i.e. closed to the lowest concentrations detected in coastal waters taking into account an analytical detection limit of diuron in sea water of around $0.002 \mathrm{mgL}^{-1}$ (Gael Durand- personal communication). The developmental toxicity of diuron has already been highlighted in various studies on fish and echinoderms. In the pink snapper (Pagrus auratus), diuron exposure led to a significant decrease in hatching and normal embryo development at the highest tested concentration of $50.00 \mathrm{\mu gL}^{-1}$ (Gagnon and Rawson, 2009), coupled with a significant increase in spinal deformities in hatched pink snappers. Effects were also observed on sea urchins at concentrations one order of magnitude higher than those tested in our study. In Paracentrotus lividus, the EC50 and NOEL were 2.39 and $0.25 \mathrm{mgL}^{-1}$ respectively concerning this endpoint (Manzo et al., 2006). In the Japanese species Hemicentrotus pulcherrimus and Anthocidaris crassipsina, the NOEL was $1 \mathrm{mgL}^{-1}$ 
(Kobayashi and Okamura, 2002). The fact that the oyster EC50 is below $0.05 \mu \mathrm{gL}^{-1}$ would tend to suggest that oysters are more sensitive to diuron toxicity than other marine invertebrates.

The developmental toxicity of chemical pollutants may involve various mechanisms. In some cases, toxic effects are directly dependent on the individual's development stage (Hamm and Hinton, 2000, Villalobos et al., 2000). Various mechanisms have been put forward for pesticides. In sea squirts, Phallusia mammillata, abnormalities associated with exposure to fungicides, Imazalil and triadimefon, appear to result from a dose-dependent accumulation of retinoic acid (Pennati et al., 2006). In the case of Irgarol, the embryotoxic effects pointed out on oysters include a negative impact on calcium homeostasy (Manzo et al., 2006). Other mechanisms have also been suggested for herbicides, paraquat and glyphosate. In xenops, the oxyradicals produced by paraquat metabolism are thought to damage the microtubules and microfilaments responsible for cell reorientation during somite formation (Vismara et al., 2000). In sea urchins, glyphosate, whether alone or contained in a formulation, has been shown to affect sea urchin development through dose-dependent inhibition of transcription and hatching at concentrations in the millimolar range (Marc et al., 2005). The mechanisms by which pesticides affect development may therefore be both species-dependent and molecule-dependent.

Of note, and as previously reported for sea urchins (Manzo et al., 2006) and blue mussels (Fitzpatrick et al., 2008) in the case of copper and biocide (diuron, irgarol) exposure, embryotoxicity appears to be a particularly sensitive endpoint for studying the effects of pollutants on development and reproduction. The embryo larval bioassay appears however as a toxicity bioassay that can presents a high variability as demonstrated previously during an inter-laboratory comparison (Stronkhorst et al., 2004). A part of variability is associated to the use of different batches of genitors that may present different pollutant sensitivity. This point was also pointed out by Damiens et al. (2004). By using larvae from two different pairs of genitors, they obtained a difference in the levels of several biomarkers in response to carbofuran exposure. These results were attributed to a difference in the physiological status of the two larvae lots but also to genetic differences. These two latter parameters are those that could explain the difference in results between the three independent embryo-larval bioassays we conducted per herbicide.

\subsection{Effects of herbicide exposure on oyster sperm}

Whatever the tested concentration, none of the studied herbicides were shown to have cytotoxic effects on oyster sperm. This could be related to a short exposure time ( $1 \mathrm{~h}$ only). As biotransformation is thought to be necessary to allow the tested pesticides to express their potential toxicity, our exposure time may have been too short for a threshold production of potentially cytotoxic by-products. The aminometylphosphonic acid (AMPA) and the $\mathrm{N}$ demethyldiuron (DCPMU) and $N$-didemethyldiuron (DCPU) are respectively the major produced metabolites of glyphosate (Motojyuku et al., 2008), and diuron (Abass et al., 2007) in human as in a wide range of organisms including bacteria. During this study, we did not directly assess the biotransformation abilities of oyster sperm to metabolize both diuron and glyphosate. However, by using PrestoBlue Cell Viability Reagent we demonstrated the ability of oyster sperm to reduce some substrates.

Conversely, as a result of its high direct oxidizing capacity, our exposure time was adequate to allow hydrogen peroxide to affect both sperm membrane integrity and mitochondrial function. It is interesting to note that the results on mitochondrial function we obtained using the luminescence ATP detection assay system and the MitoTracker Red CMXRos for flow cytometry analysis were well-harmonized. 
In the course of our study, glyphosate appeared to have no genotoxic effects on oyster sperm either alone or incorporated in a formulation. Little data demonstrating the genotoxicity of glyphosate exists in the literature, although genotoxic effects have systematically been observed at very high concentrations and by exposing isolated cells or whole individuals. A significant increase in single strand breakage was hence reported in Hep-2 cells following 4 and 24-h exposure to $0.5 \mathrm{gL}^{-1}$ (Mañas et al., 2009b) and $5 \mathrm{mgL}^{-1}$ of glyphosate (Gasnier et al., 2009) respectively. A similar genotoxic endpoint was observed in fish erythrocytes following 6 to 96 -h exposure to $10 \mathrm{mgL}^{-1}$ (Çavas and Könen, 2007, Cavalcante et al., 2008). Genotoxicity was also observed when glyphosate was tested in the Roundup formulation. In tadpoles, the Roundup formulation was shown to have genotoxic effects on erythrocytes following a 24- $\mathrm{h}$ exposure to a concentration of $6.75 \mathrm{mgL}^{-1}$ (Clements et al., 1997).

As for many other pesticides, the potential genotoxic effects of glyphosate appear to be mediated by the production of oxyradicals during its biotransformation process, as indicated by a concomitant increase in antioxidant defence and lipid peroxidation activities (Manas et al., 2009b). It is interesting to note that in rodent, AMPA, which is the major metabolite of glyphosate, has been shown to produce different kinds of DNA damage both in vitro and in vivo (strand breakage in Hep-2 cells, micronuclei in mice following i.p. injections) at respective concentrations of $2.5 \mathrm{mM}$ and $2 \times 100 \mathrm{mg} / \mathrm{kg}$ upwards (Manas et al., 2009a). AMPA could hence account for much of glyphosate genotoxicity. The absence of genotoxic effects on oyster sperm observed in this study could be the result of our short exposure time and/or the low concentrations selected to achieve an environmentally-relevant approach.

Unlike glyphosate, diuron was shown to have genotoxic effects on oyster sperm from our lowest tested concentration of $0.05 \mathrm{\mu gL}^{-1}$ upwards. The genotoxicity of diuron with regards to aquatic species has already been demonstrated at environmentally-relevant concentrations. Despite the fact that it was not tested individually, diuron $\left(1 \mu \mathrm{gL}^{-1}\right)$ was shown to have genotoxic effects on fish erythrocytes following a 26-day exposure to a mixture containing axoxystrobine $\left(0.5-1.0 \mu \mathrm{gL}^{-1}\right)$ (Bony et al., 2008). In oysters, irreversible genetic damage such as chromosome number changes were also observed following the exposure of adult oysters to $0.3 \mathrm{\mu gL}^{-1}$ of diuron for 11 weeks (Bouilly et al., 2007). In the latter study, the aneuploidy effect persisted to the next generation. With regards to the concentrations tested in this study, diuron appears to be genotoxic but not cytotoxic in oyster sperm. The measurement of single strand breakage indicated an attack on DNA by oxyradicals thought to be produced during diuron biotransformation. The results of the main effects ANOVA showed diuron to have toxic effects on oyster embryo (embryotoxicity) and on sperm (genotoxicity) at the same and very low concentration of $0.05 \mathrm{mg}^{-1}$. As genotoxic impact on reproductive success is difficult to assess, it is important to determine how damage to sperm DNA can affect its function, and how the transmission of damaged DNA can impair development.

The results we obtained by flow cytometry allowed us to answer that question partially. As previously described (Gillan et al., 2005, Martínez-Pastor et al., 2010), flow cytometry is a foremost technique for sperm assessment. This method has already been used to assess gamete quality in oysters, in the aim of developing cryopreservation protocols (PaniaguaChávez et al., 2006). It has also been used to study the effects of pollutants and UV irradiation on the sperm of oysters and other invertebrates (Lu and Wu, 2005, Favret and Lynn, 2010). Sperm mitochondrial function and acrosomal membrane integrity were selected as good indicators of sperm function. ATP in sperm flagella is consumed to provide energy for motility; it is synthesized by mitochondrial respiration and mainly stored prior to activation. The acrosome plays an important role at the sperm-egg binding site: its activation (acrosomal reaction) prompts the exocytosis of its enzyme contents (e.g. acid glycohydrolases, proteases, esterases, etc.), hence enabling the acrosome-reacted spermatozoa to penetrate the zona pellucida and fertilize the egg. In our study, diuron 
exposure had no effect on mitochondrial function or acrosomal membrane integrity, which are the key parameters governing fertilization. However, our genotoxicity control significantly affected these parameters. As the toxicity of hydrogen peroxide is exclusively mediated by oxidative stress, an unbalanced production of oxyradicals can potentially affect both sperm DNA and sperm function in oysters. In the case of diuron, the induced oxidative stress may have sufficed to damage sperm DNA, but been insufficient to affect sperm function in terms of mitochondrial function and acrosomal membrane integrity. We can note that exposure to pesticide formulations (Bayluscide and Roundup Ready To-Use-Plus ${ }^{\circledR}$, respectively formulated with the active substances niclosamide and glyphosate) resulted in significant effects on both of these parameters in oysters (C. virginica), freshwater mussels $(D$. polymorpha) and sea urchins ( $L$. variegatus), with differences according to species and molecules (Favret and Lynn, 2010). For example, a 20-min exposure to Bayluscide significantly affected mitochondrial function after a 20 -min sperm exposure at $62.5 \mu \mathrm{gL}^{-1}, 250$ $\mu \mathrm{gL}^{-1}$ and $1 \mathrm{mgL}^{-1}$ in oysters, sea urchins and freshwater mussels respectively. Although Bayluscide significantly affected oyster acrosomal membrane integrity at a concentration of 1 $\mathrm{mgL}^{-1}$, Roundup exposure produced no effect on this parameter, even at the highest tested concentration of $16 \mathrm{mgL}^{-1}$. Similarly to embryotoxicity, spermiotoxicity appears to be both species-dependent and molecule-dependent.

\section{Conclusion}

The various embryo-larval bioassays and spermiotoxicity experiments carried out in the course of our study revealed differing results, possibly due to the influence of oyster genitor lots on biological responses. As various authors have pointed out, it appears necessary to test different oyster couples/individuals when performing bioassays, in order to take into account sensitivity differences which may be partly owed to genetic polymorphism.

Glyphosate and Roundup had no effect on oyster sperm and embryos in our experiments. The commercial formulation did not appear to be more toxic than glyphosate - the active substance - in terms of embryotoxicity, sperm DNA damage and sperm function defects. However, it will be interesting to study the effects of the main metabolite of glyphosate, AMPA, before taking a stance on the potential environmental threat represented by glyphosate for broadcast spawners.

Conversely, diuron appears to have embryotoxic and genotoxic effects on oyster sperm at environmentally-realistic concentrations; these effects were observed from $0.05 \mathrm{\mu gL}^{-1}$ upwards. The presence of diuron in coastal waters therefore appears to represent a threat to oyster populations. As diuron can provoke developmental defects, it may significantly affect oyster recruitment rates; it can also cause significant damage to sperm DNA. Even though our initial findings showed no impact on sperm function (mitochondrial function and acrosomal membrane integrity), we need to investigate to what extent fertilization rates may be affected, and determine the possible consequences of damaged DNA transmission on oyster development and physiological performance.

\section{Acknowledgments}

This work was funded by the French Research Institute for Sea Exploration (Ifremer). 


\section{References}

Abass, K., Reponen, P., Turpeinen, M., Jalonen, J., Pelkonen, O. (2007). Characterization of Diuron $N$-Demethylation by Mammalian Hepatic Microsomes and cDNA-Expressed Human Cytochrome P450 Enzymes. Drug. Metab. Disp. 35, 1634-1641

Akcha, F., Vincent-Hubert, F., Leszkowicz, A., 2003. Potential value of the Comet assay and DNA adduct measurement in dab (Limanda limanda) for the assessment of in situ exposure to genotoxic compounds. Mutat. Res. Genet. Toxicol. Environ. Mutagen. 534, 21-32.

Bellas, J., Granmo, A., Beiras, R., 2005. Embryotoxicity of the antifouling biocide zinc pyrithione to sea urchin (Paracentrotus lividus) and mussel (Mytilus edulis). Mar. Poll. Bull. 50, 1382-1385.

Beiras, R and Bellas, J., 2008. Inhibition of embryo development of the Mytilus galloprovincialis marine mussel by organic pollutants; assessment of risk for its extensive culture in the Galician Rias. Aquacult. 277, 208-212.

Binelli, A., Riva, C., Cogni, D., Provini, A., 2008. Assessment of the genotoxic potential of benzo(a)pyrene and pp'-dichlorodiphenyldichloroethylene in Zebra mussel (Dreissena polymorpha). Mutat. Res., Genet. Toxicol. Environ. Mutagen. 649, 135-145.

Bony, S., Gillet, C., Bouchez, A., Margoum, C., Devaux, A., 2008. Genotoxic pressure of vineyard pesticides in fish: field and mesocosm surveys. Aquat. Toxicol. 89, 197-203.

Bouilly, K., Bonnard, M., Gagnaire, B., Renault, T., Lapègue, S., 2007. Impact of diuron on aneuploidy and hemocyte parameters in Pacific oyster, Crassostrea gigas. Arch. Environ. Contam. Toxicol. 52, 58-63.

Bortagaray, V., Cruces Aramburu, R., Barrios, L., Ojeda, P., del Puerto, G., Rodríguez-Ithurralde, D., 2010. Embryotoxicity and teratogenesis in zebrafish embryos exposed in vitro to glyphosate-type herbicides. J. Dev. Toxicol. http://drithurralde.wordpress.com/2010/06/04/15.

Burgeot, T., Gagnaire, B., Renault, T., Haure, J., Moraga, D., David, E., Boutet, I., Sauriau, P. G., Malet, N., Bouchet, V., Le Roux, A., Lapègue, S., Bouilly, K., Le Moullac, G., Arzul, G., Knoery, J., Quiniou, F., Barcher, C., Soletchnick, P., 2008. Oyster summer morality risks associated with environmental stress. In : Summer mortality of Pacific oyster Crassostrea gigas. The Morest project. Samain J.F. and McCombie H. (eds). Éd. Ifremer/Quæ, pp.107151.

Çavas, T., and Könen, S., 2007. Detection of cytogenetic and DNA damage in peripheral erythrocytes of goldfish (Carassius auratus) exposed to a glyphosate formulation using the micronucleus test and the comet assay. Mutagen. 22, 263-268.

Cavalcante, D. G. S. M., Martinez, C. B. R., Sofia, S. H., 2008. Genotoxic effects of Roundup ${ }^{\circ}$ on the fish Prochilodus lineatus. Mutat. Res. Genet. Toxicol. Environ. Mutagen. 655, 41-46.

Clements, C., Ralph, S., Petras, M., 1997. Genotoxicity of select herbicides in Rana catesbeiana tadpoles using the alkaline single-cell gel DNA electrophoresis (comet) assay. Environ. Mol. Mutagen. 29, 277-88.

Damiens, G., His, E., Gnassia-Barelli, M., Quiniou, F., Romeo, M. (2004). Evaluation of biomarkers in oyster larvae in natural and polluted conditions. Comp. Biochem. Physiol. 138C, 121-128.

Favret, K. P., and Lynn, J. W., 2010. Flow-cytometric analyses of viability biomarkers in pesticide-exposed sperm of three aquatic invertebrates. Arch. Environ. Contam. Toxicol. 58, 973-984. 
Fitzpatrick, J. L., Nadella, S., Bucking, C., Balshine, S., Wood, C. M., 2008. The relative sensitivity of sperm, eggs and embryos to copper in the blue mussel (Mytilus trossulus). Comp. Biochem. Physiol. 147, 441-449.

Gagnaire, B., Thomas-Guyon, H., Burgeot, T., Renault, T., 2006. Pollutant effects on Pacific oyster, Crassostrea gigas (Thunberg), hemocytes: screening of 23 molecules using flow cytometry, Cell Biol. Toxicol. 22, 1-14.

Gagnaire, B., Gay, M., Huvet, A., Daniel, J-. Y., Saulnier, D., Renault, T., 2007. Combination of a pesticide exposure and a bacterial challenge: In vivo effects on immune response of Pacific oyster, Crassostrea gigas (Thunberg). Aquat. Toxicol. 84, 92-102.

Gagnon, M. M., and Rawson, C. A., 2009. Diuron increases spinal deformity in early-life-stage pink snapper Pagrus auratus. Mar. Poll. Bull. 58, 1078-1079.

Galgani, F., Senia, J., Guillou, J. L., Laugier, T., Munaron, D., Andral, B., Guillaume, B., Coulet, E., Boissery, P., Brun, L., Bertrandy, M. C., 2009. Assessment of the environmental quality of French continental Mediterranean lagoons with oyster embryo bioassay. Arch. Environ. Contam. Toxicol. 57, 540-551.

Gillian, L., Evans, G., Maxwell, W. M. C., 2005. Flow cytometric evaluation of sperm parameters in relation to fertility potential. Theriogenol. 63, 445-457.

GESAMP, Joint Group of Experts on the Scientific Aspects of Marine Environmental Protection, 2002. The revised GESAMP hazard evaluation procedure for chemical substances carried by ships. Reports \& Studies, $n^{\circ} 64$.

Hamm, J. T., and Hinton, E. D., 2000. The role of development and duration of exposure to the embryotoxicity of diazinon. Aquat. Toxicol. 48, 403-418.

Kobayashi, N., and Okamura, H., 2002. Effects of new antifouling compounds on the development of sea urchin. Mar. Poll. Bull. 44, 748-751.

Lamoree, M. H., Swart, C. P., van der Horst, A., van Hattum, B., 2002. Determination of diuron and the antifouling paint biocide Irgarol 1051 in Dutch marinas and coastal waters. J. Chromatogr. A 970, 183-190.

Lenkowski, J. R., Sanchez-Bravo, G., McLaughlin, K. A., 2010. Low concentrations of atrazine, glyphosate, 2,4-dichlorophenoxyacetic acide, and triadimefon exposures have diverse effects on Xenopus laevis organ morphogenesis. J. Environ. Sci. 22, 1305-1308.

Lu, X. Y., and Wu, R. S. S., 2005. Ultraviolet damages sperm mitochondrial function and membrane integrity in the sea urchin Anthocidaris crassispina. Ecotoxicol. Environ. Safety 61, 53-59.

Lyons, B. P., Pascoe, C. K., McFadzen, I. R. B., 2002. Phototoxicity of pyrene and benzo[a]pyrene to embryo-larval stages of the pacific oyster Crassostrea gigas. Mar. Environ. Res. 54, 627-631.

Mañas, F., Peralta, L., Raviolo, J., Garcia Ovando, H., Weyers, A., Ugnia, L., Gonzalez Cid, M., Larripa, I., Gorla, N., 2009a. Genotoxicity of AMPA, the environmental metabolite of glyphosate, assessed by the comet assay and cytogenetic tests. Ecotoxicol. Environ. Safety 72, 834-837.

Mañas, F., Peralta, L., Raviolo, J., Garcia Ovando, H., Weyers, A., Ugnia, L., Gonzalez Cid, M., Larripa, I., Gorla, N., 2009b. Genotoxicity of glyphosate assessed by the comet assay and cytogenetic tests. Environ. Toxicol. Pharmacol. 28, 37-41.

Manzo, S., Buono, S., Cremisini, C., 2006. Toxic effects of Irgarol and Diuron on sea urchin Paracentrotus lividus early development, fertilization, and offspring quality. Arch. Environ. Contam. Toxicol. 51, 61-68. 
Marc, J., Le Breton, M., Cormier, P., Morales, J., Bellé, R., Mulner-Lorillon, O., 2005. A glyphosatebased pesticide impinges on transcription. Toxicol. Appl. Pharmacol. 203, 1-8.

Marchetti, C., Jouy, N., Leroy-Martin, B., Defossez, A., Formstecher, P., Marchetti, P., 2004. Comparison of four fluorochromes for the detection of the inner mitochondrial membrane potential in human spermatozoa and their correlation with sperm motility. Hum. Reprod. 19, 2267-2276.

Martínez-Pastor, F., Mata-Campuzano, M., Àlvarez-Rodríguez, M., Àlvarez, M., Anel, L., de Paz, P., 2010. Probes and techniques for sperm evaluation by flow cytometry. Reprod. Dom. Anim. 45, 67-78.

Morley, N. J., 2009. Interactive effects of infectious diseases and pollution in aquatic molluscs. Aquat. Toxicol. 96, 27-36.

Motojyuku, M;, Saito, T., Akieda, K., Otsuka, H., Yamamoto, I., Inokuchi, S. (2008). Determination of glyphosate, glyphosate metabolites, and glufosinate in human serum by gas chromatography-mass spectrometry. J. Chrom. B. 875, 509-514.

Munaron, D., 2004. Etude des apports en herbicides et en nutriments par la Charente : Modélisation de la dispersion de l'atrazine dans le bassin de Marennes-Oléron. Thèse de Doctorat, Université Pierre et Marie Curie Paris V.

Okamura, H., Aoyama, I., Ono, Y., Nishida, T., 2003. Antifouling herbicides in the coastal waters of western Japan. Mar. Poll. Bull. 47, 59-67.

Paniagua-Chávez, C. G., Jenkins, J., Segovia, M., Tiersch, T. R., 2006. Assessment of gamete quality for the eastern oyster (Crassostrea virginica) by use of fluorescent dyes. Cryobiol. 53, 128-138.

Pennati, R., Groppelli, S., Zega, G., Biggiogero, M., De Bernardi, F., Sotgia, C., 2006. Toxic effects of two pesticides, Imazalil and Triadimefon, on the early development of the ascidian Phallusia mammillata (Chordata, Ascidiacea). Aquatic Toxicol. 79, 205-212.

Quiniou, F., Damiens, G., Gnassia Barelli, M., Geffard, A., Mouneyrac, C., Budzinski, H., Romeo, M., 2007. Marine water quality assessment using transplanted oyster larvae. Environ. Intern. 33, 27-33.

Reynaud, S., Raveton, M., Ravanel, P., 2008. Interactions between immune and biotransformation systems in fish: A review. Aquatic. Toxicol. 87, 139-145.

Rodríguez, E. M., Medesani, D. A., Fingerman, M., 2007. Endocrine disruption in crustaceans due to pollutants: A review. Comp. Biochem. Physiol. Part A: Mol. Integr. Physiol. 146, 661-671.

Salaberria, I., Hansen, B. H., Asensio, V., Olsvik, P. A., Andersen, R. A., Jenssen, B. M., 2009. Effects of atrazine on hepatic metabolism and endocrine homeostasis in rainbow trout (Oncorhynchus mykiss). Toxicol. Appl. Pharmacol. 234, 98-106.

Samain, J. F., Dégremont, L., Soletchnik, P., Haure, J., Bédier, E., Ropert, M., Moal, J., Huvet, A., Bacca, H., Van Wormhoudt, A., Delaporte, M., Costil, K., Pouvreau, S., Lambert, C., Boulo, V., Soudant, P., Nicolas, J-. L., Le Roux, F., Renault, T., Gagnaire, B., Geret, F., Boutet, K., Burgeot, T., Boudry, P., 2007. Genetically based resistance to summer mortality in the Pacific oyster (Crassostrea gigas) and its relationship with physiological, immunological characteristics and infection processes. Aquacult. 268, 227-243.

Sánchez-Rodriguez, A., Sosa-Ferrera, Z., Santana-del Pino, A., Santana-Rodriguez, J. J., 2011. Probabilistic risk assessment of common booster biocides in surface waters of the harbours of Gran Canaria (Spain). Mar. Poll. Bull. 62, 985-991.

Stronkhorst, J., Ciarelli, S., Schipper, C. A., Postma, J. F., Dubbeldam, M., Vangheluwe, M., Brils, J. M., Hooftman, R. (2004). Inter-laboratory comparison of five marine bioassays for evaluating the toxicity of dredged material. Aquat. Ecosyst. Health. Manag. 7, 147-159. 
Tate, T. M., Spurlock, J. O., Christian, F. A., 1997. Effect of glyphosate on the development of Pseudosuccinea columella snails. Arch. Environ. Contam. Toxicol. 33, 286-289.

Thomas K. V., McHugh, M., Waldock, M., 2002. Antifouling paint booster biocides in UK coastal waters: inputs, occurrence and environmental fate. Sci. Total Environ. 293, 117-127.

UIPP, 206 (http://www.uipp.org).

Villalobo, S. A., Hamm, J. T., Teh, S. J., Hinton, D. E., 2000. Thiobencarb-induced embryotoxicity in medaka (Oryzias latipes): stage-specific toxicity and the protective role of chorion. Aquat. Toxicol. 48, 309-326.

Vismara, C., Battista, V., Vailati, G., Bacchetta, R., 2000. Paraquat induced embryotoxicity on Xenopus laevis development. Aquat. Toxicol. 49, 171-179.

Wessel, N., Rousseau, S., Caisey, X., Quiniou, F., Akcha, F., 2007. Investigating the relationship between embryotoxic and genotoxic effects of benzo[a]pyrene, 17a-ethinylestradiol and endosulfan on Crassostrea gigas embryos. Aquat. Toxicol. 85, 133-142.

Woodburn, A., 2000. Glyphosate: production, pricing and use worldwide. Pest Manag. Sci. 56, 309-312. 
Table 1: Selected range of diuron and glyphosate concentrations tested during the study

\begin{tabular}{|l|c|c|}
\hline Chemicals & $\begin{array}{c}\text { Tested concentrations } \\
\left(\mu \text { gactive substance } ~^{-1}\right)\end{array}$ & $\begin{array}{r}\text { Environmental concentrations } \\
\left(\mu \text { g active substance } L^{-1}\right)\end{array}$ \\
\hline Diuron & $0.05 ; 0.10 ; 0.25 ; 0.50,1.5^{*}$ & $\begin{array}{r}0.02-0.20 \text { (Sánchez-Rodríguez et al., 2011) } \\
0.03-3.05 \text { (Okamura et al., 2003) } \\
0.09-1.13 \text { (Lamoree et al., 2002) } \\
0.03-1.25 \text { (Thomas et al., 2002) }\end{array}$ \\
\hline Glyphosate & $0.5 ; 1.0,1.5 ; 2.5 ; 5.0$ & $0.1-1.2$ (Burgeot et al., 2007) \\
\hline Roundup & $0.5 ; 1.0,1.5 ; 2.5 ; 5.0$ & \\
\hline
\end{tabular}

*this concentration was not tested during the embryotoxicity study 


\section{Figures}

Figure 1: Results from the three independent embryo-larval bioassays concerning the effect of diuron exposure on oyster development ( $\left.{ }^{*}: p<0.05\right)$.

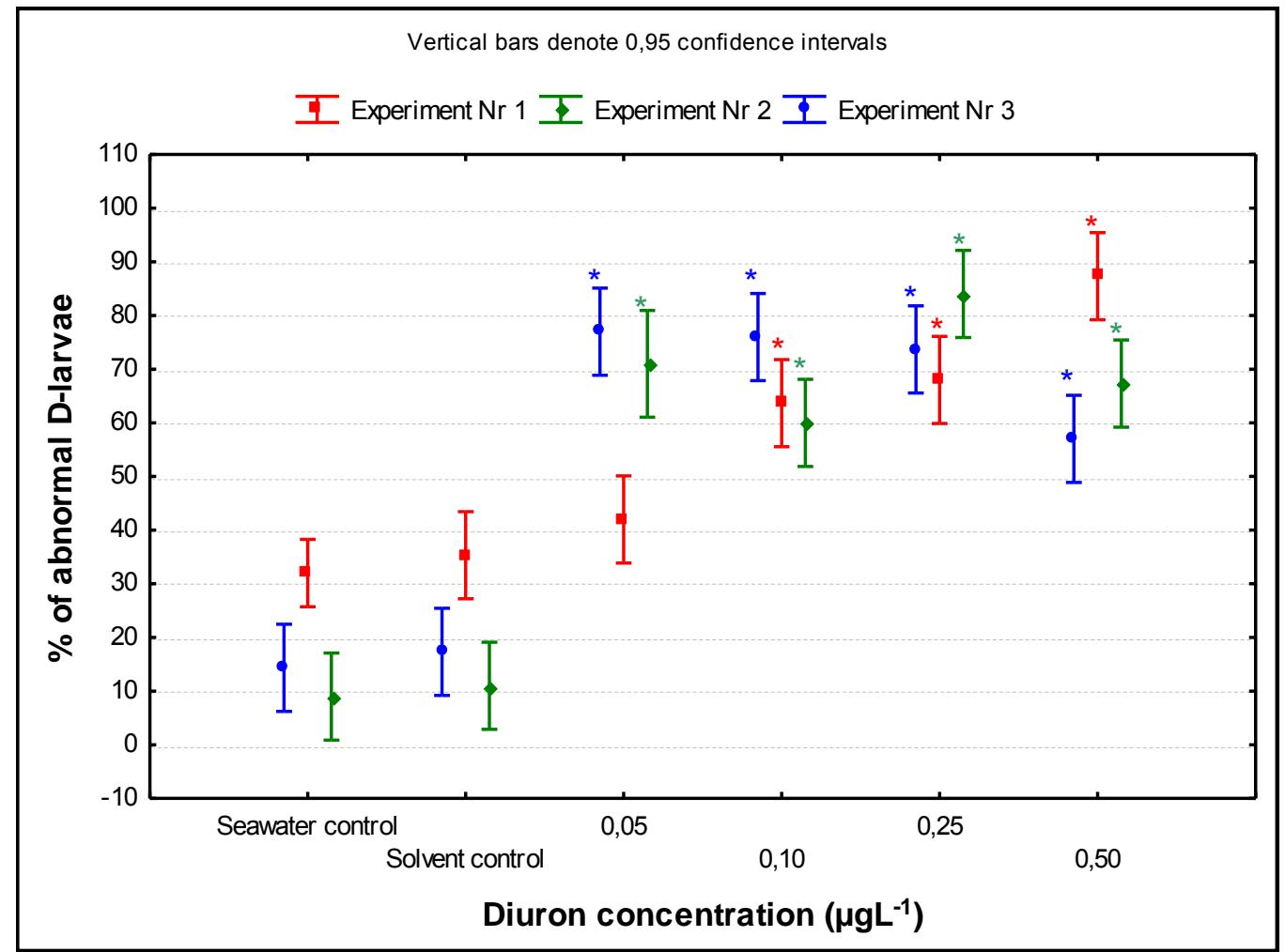

Figure 2: Main embryotoxic effect of diuron: results from data collected from the 3 independent bioassays $\left({ }^{*}: p<0.05\right)$.

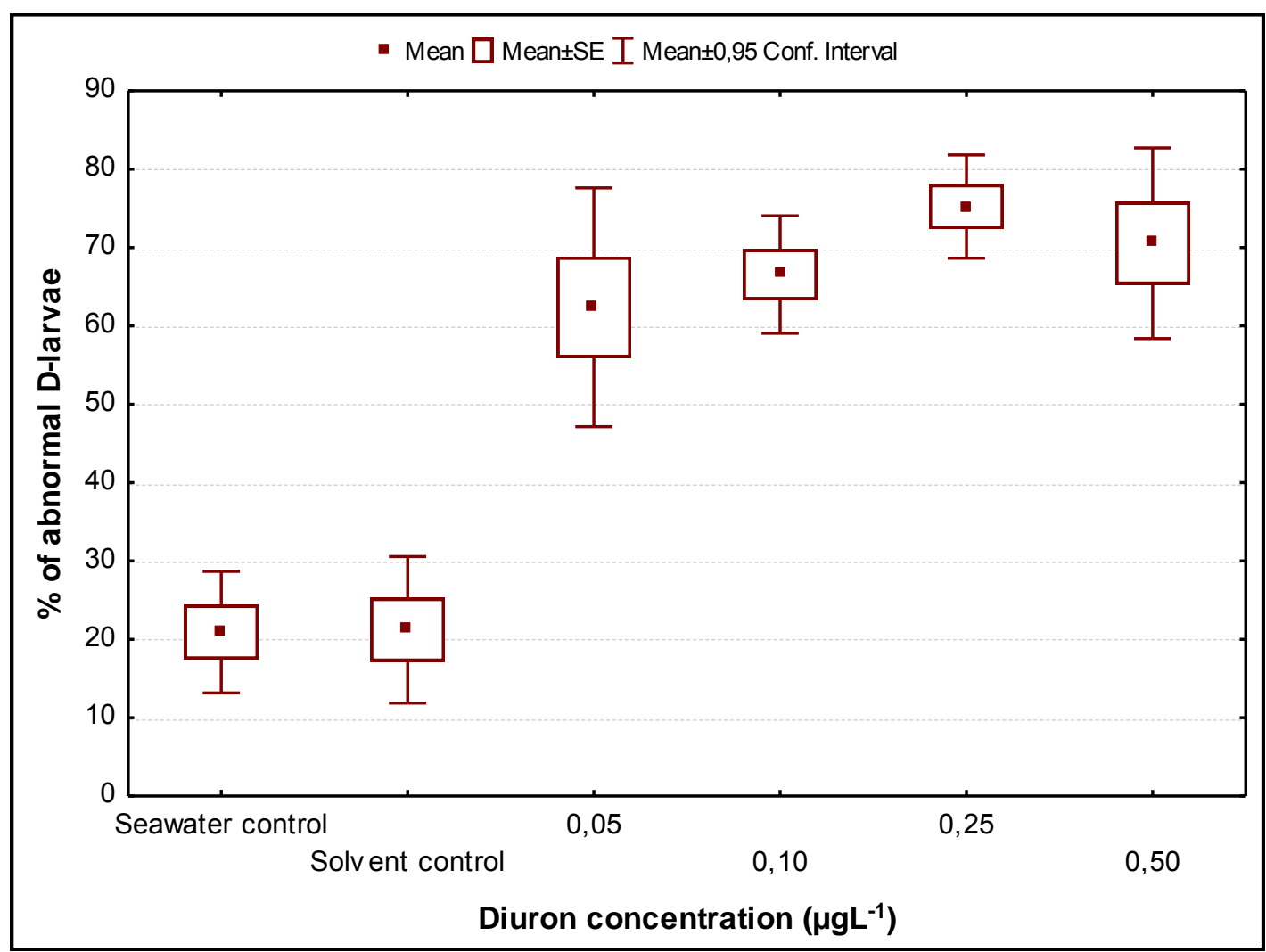


Figure 3: Results from the three independent embryo-larval bioassays concerning the effect of glyphosate exposure on oyster development (*: $p<0.05)$.

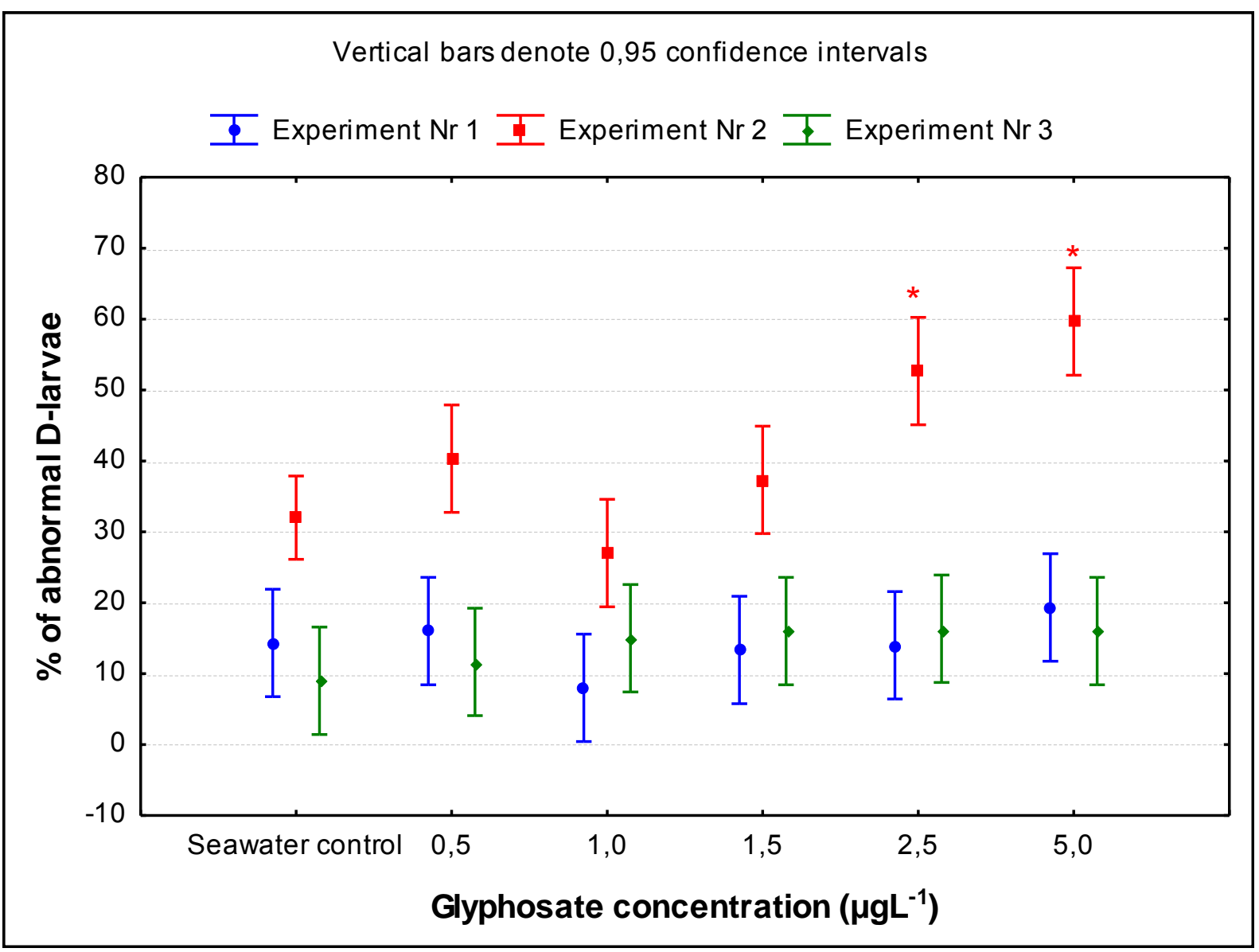

Figure 4: Main embryotoxic effect of glyphosate: results from data collected from the 3 independent bioassays $\left({ }^{*}: p<0.05\right)$.

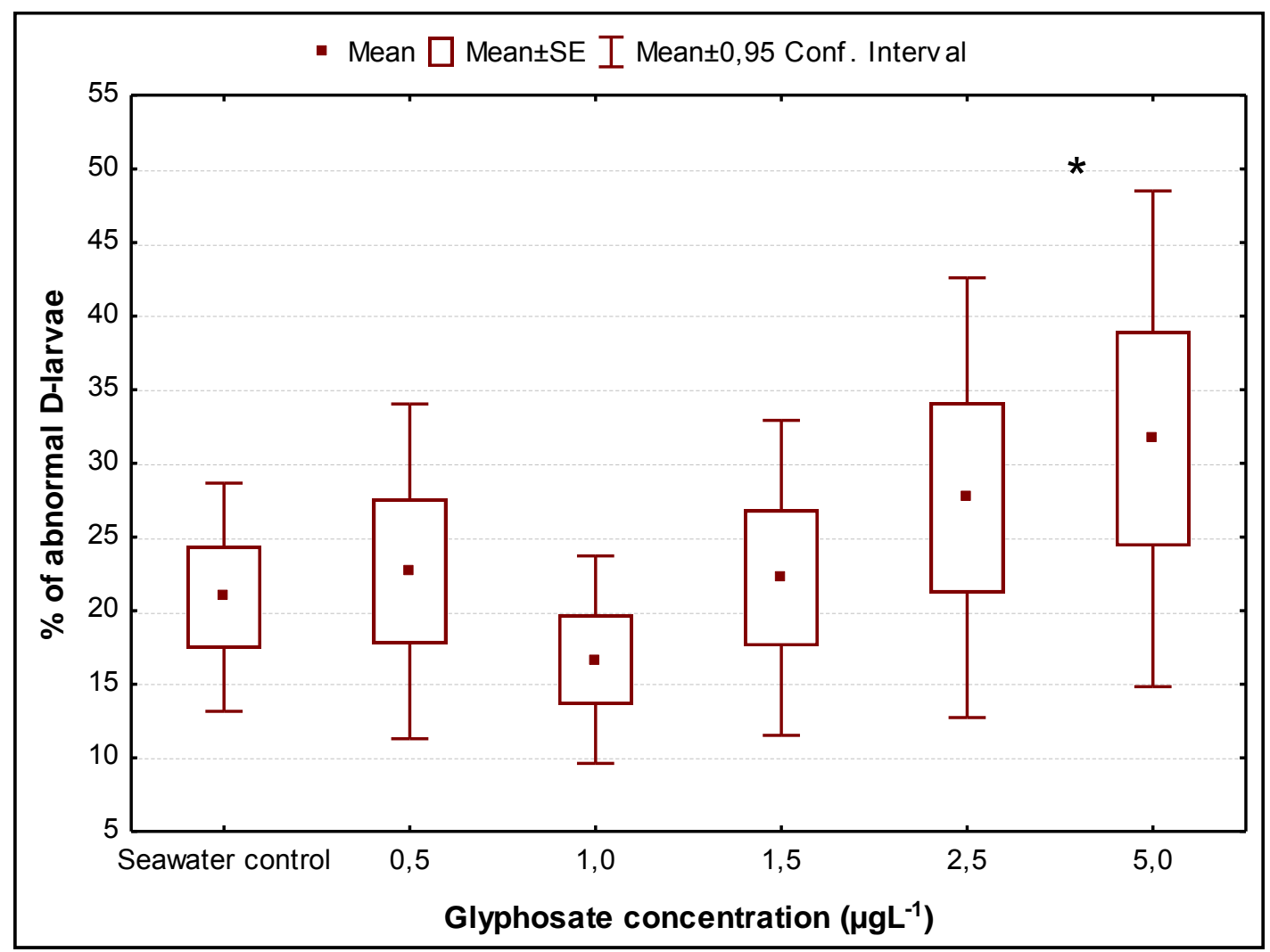


Figure 5: Main embryotoxic effect of Roundup: results from data collected from the 3 independent bioassays

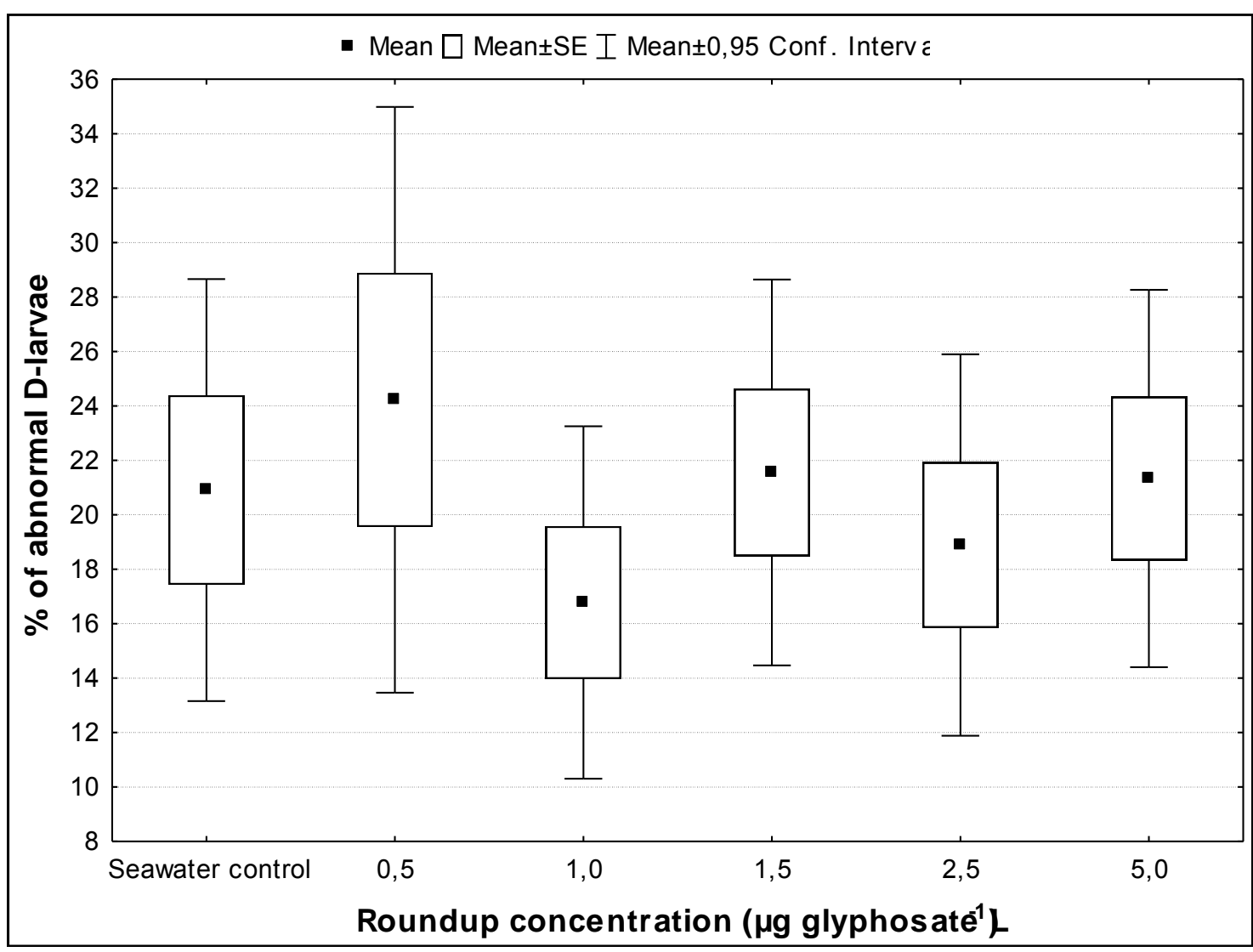


Figure 6: Results of the viability tests: case of diuron. Results from the titration of intracellular ATP (A) and from the Prestoblue Cell viability assay $(B)\left(^{*}: p<0.05\right)$.
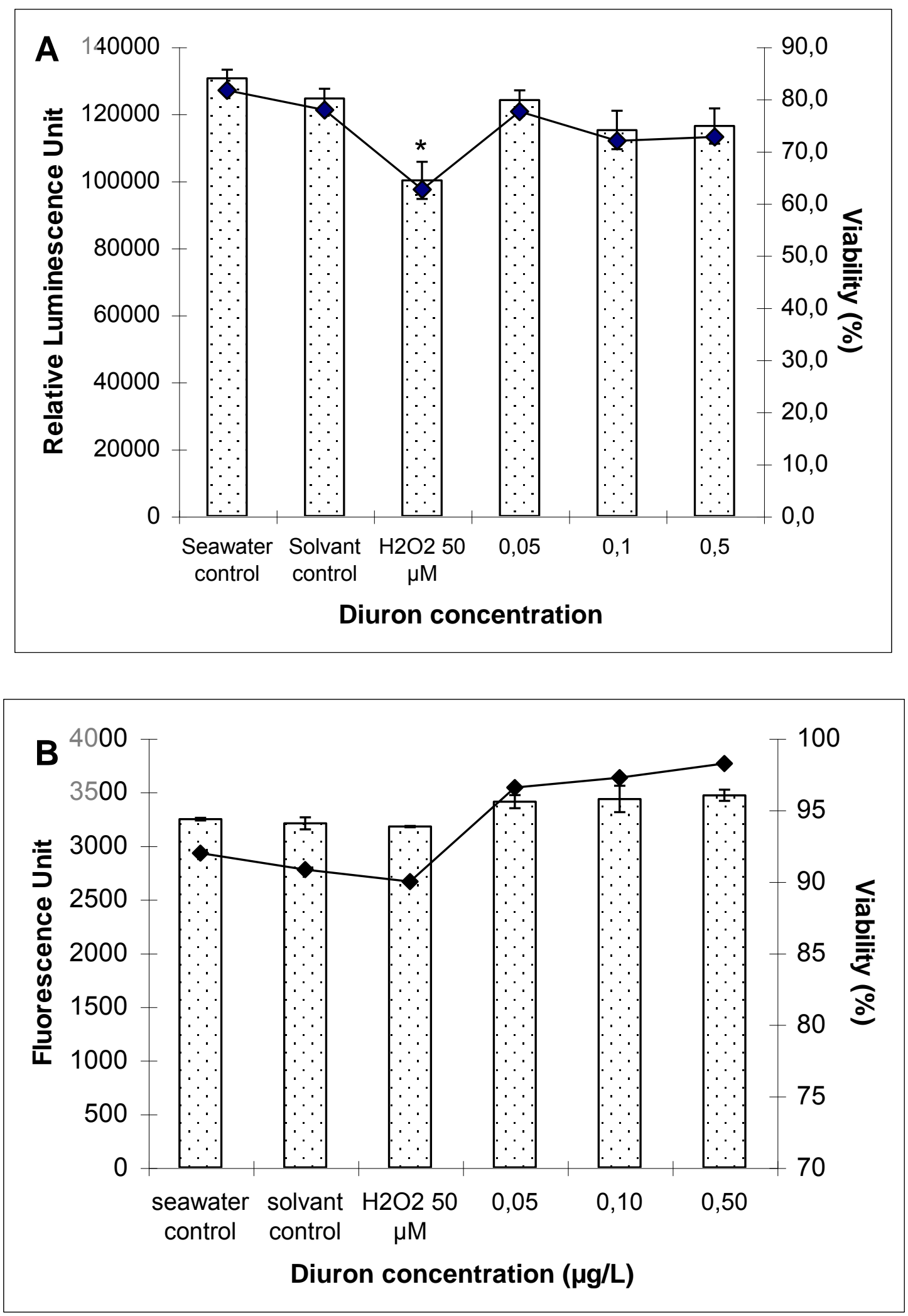
Figure 7: Increase in the level of DNA strand breaks of oyster spermatozoa following exposure to the direct genotoxicant $\mathrm{H}_{2} \mathrm{O}_{2}\left({ }^{*}: \mathrm{p}<0.05\right)$.

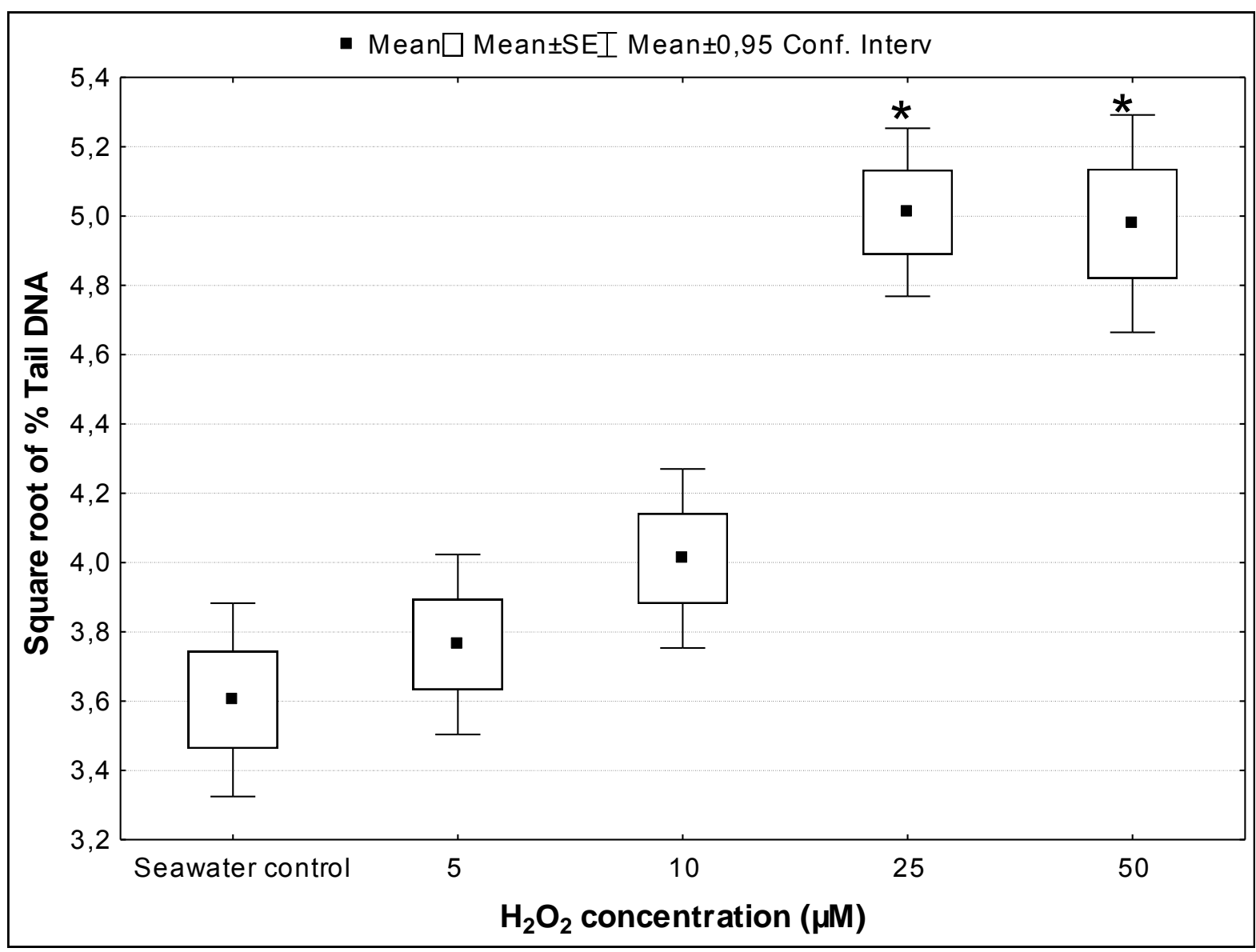


Figure 8: Effects of diuron exposure on the DNA integrity of oyster spermatozoa: results from the three independent experiments and from the main effects ANOVA $\left({ }^{*}: p<0.05\right)$.

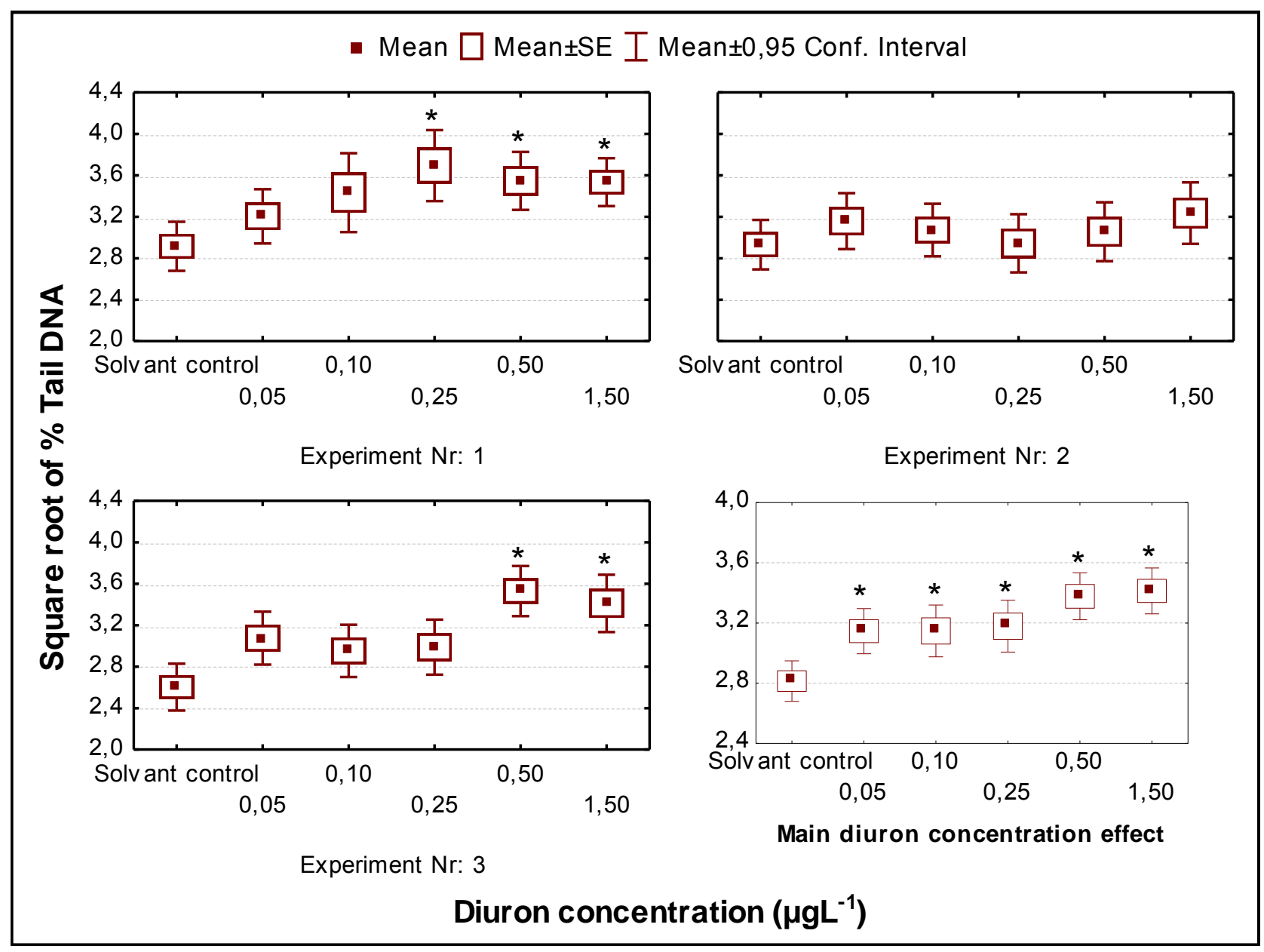


Figure 9: Effects of diuron exposure on sperm viability $(A)$, and sperm function as assessed by mitochondria membrane integrity $(B)$ and acrosomal membrane integrity $(C)\left({ }^{*}: p<0.05\right)$.
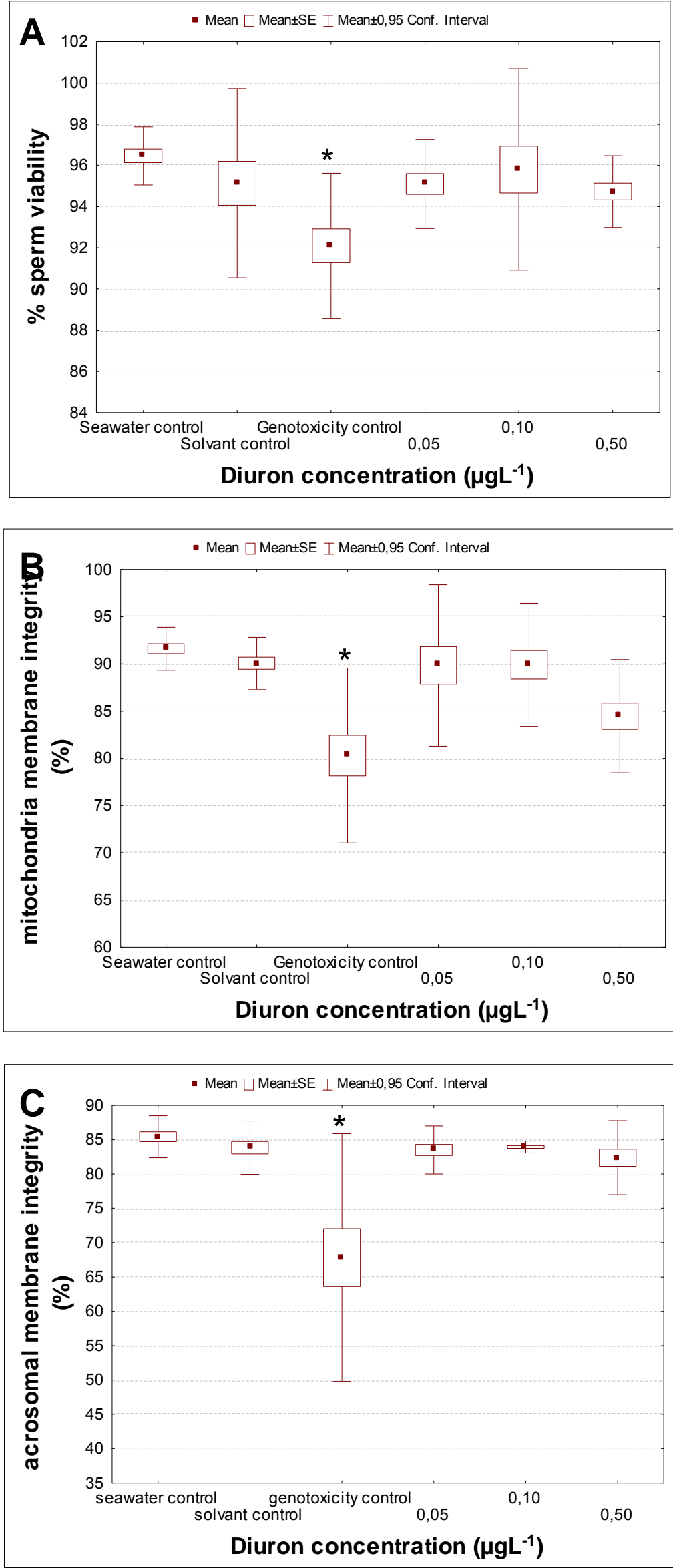